\title{
GESTÃO DE RECURSOS EDUCACIONAIS: UM RELATO DE CASO
}

\author{
Raymundo Carlos Machado Ferreira Filho ${ }^{1}$ \\ Nilo César Consoli** \\ Fernando Schnaid ${ }^{* * *}$ \\ Rosa Maria Vicari "
}

Resumo: neste artigo descreve-se o processo de produção de recursos educacionais e o uso de Tecnologias da Informação e Comunicação (TICs), relacionando-as ao uso do ensino em Engenharia Geotécnica. Este trabalho desenvolveu um sistema de informações, denominado ENGEO, baseado num modelo que integra recursos educacionais produzidos em diferentes formatos eletrônicos armazenados em um repositório e um software baseado na Web para gestão destes recursos e das informações do curso. Este aplicativo foi desenvolvido para o curso de Engenharia Geotécnica, particularizado para Engenharia de Fundações.

Palavras-chave: Ensino de Engenharia; Informática na Educação; Engenharia Geotécnica; Tecnologias da Informação e Comunicação; Tecnologia Educacional.

Abstract: this work describes the production process of educational technologies and Communication and Information Technologies (TICs), relating them it the use of education in Geotechnical Engineering. This work developed an information system, called ENGEO, based on a model that integrates produced educational resources in different electronic formats stored in a repository and software based on the Web for management of these resources and the information of the course. The ENGEO was developed for the course of Geotechnical Engineering, especially for Foundations Engineering.

Palavras-chave: Engineering Education; Computer Science in Education; Geotechnical Engineering; Information and Communication Technologies; Educational Technology.

\section{INTRODUÇÃO}

Em todas as instituições de ensino, a organização dos dados, das informações, e dos recursos educacionais dos cursos e suas disciplinas tem consumido grande parte dos esforços dos educadores e de grupos de pesquisa preocupados em melhorar a qualidade do ensino e com o impacto das Tecnologias da Informação e Comunicação (TICs) nos processos educacionais, em especial, no caso deste artigo, no ensino-aprendizagem em áreas tecnológicas.

A gestão de recursos educacionais através da Web representa hoje um grande mercado internacional. Muitas empresas do setor de desenvolvimento de softwares exploram o

\footnotetext{
${ }^{1}$ Doutorando do Programa de Pós-graduação em Informática na Educação (PGIE) - Universidade Federal do Rio Grande do Sul - paka@ufrgs.br.

** Professor do Departamento de Engenharia Civil (PPGEC) da Universidade Federal do Rio Grande do Sul, PhD. (Concordia University, Canadá, 1991). Pesquisador do CNPq. Consultor "AD HOC" do CNPq e FAPESP consoli@ufrgs.br.

*** Professor do Departamento de Engenharia Civil (PPGEC) da Universidade Federal do Rio Grande do Sul, PhD. (Oxford University, U.K., 1990). Pesquisador do CNPq; Coordenador do Laboratório de Ensaios Geotécnicos e Geoambientais (LEGG); Professor visitante das Universidades de Oxford, U.K.; Newcastle, AUS; Universidade Nacional del Nordeste, ARG, Universidad de la Republica, UR - fernando@ufrgs.br.

*.** Professora adjunta do Departamento de Informática da Universidade Federal do Rio Grande do Sul, graduação e pós-graduação (CPGCC) desde 1987. Coordenadora do curso de Pós-graduação em Informática na Educação da UFRGS desde 1997. Pós-doutorado na Universidade de Leeds, UK, 1997. Grupo CBLU - Computer Base Learning Unit.rosa@inf.ufrgs.br.

V.3 № 1, Maio, 2005
} 
mercado educacional, propondo soluções de sistemas de gestão de cursos que agregam TICs, chamados LMS (Learning Management Systems). Entretanto, são soluções planejadas para atenderem a demanda de qualquer professor ou curso da mesma forma, de forma genérica, cabendo ao professor definir as estratégias de utilização de acordo com as ferramentas disponíveis no LMS.

Deve-se entretanto salientar que soluções soluções desenvolvidas comercialmente não dão conta da complexidade envolvida na estruturação do conhecimento envolvido nas áreas tecnológicas e tampouco oferecem todas as possibilidades tecnológicas integradas em um único ambiente. Na experiência do autor, em análise de sistemas de gestão de cursos baseados na Web, entre softwares proprietários e baseados em Open Source e Free Software, nenhum deu conta de oferecer todos os recursos necessários tanto à estruturação do material quanto à gestão do conteúdo de um curso como o de Fundações. É possível estender esta afirmação para o domínio da Engenharia Geotécnica. Cursos desta natureza implicam conteúdo extenso, complexo e apoiado em conhecimento altamente estruturado, além de implicar necessidades de apoio à visualização de conceitos e documentação de casos de obra. Também não se observou na literatura, em âmbito nacional e internacional, nenhuma descrição relativa à aplicação de TICs e de sistemas de gestão baseados na Web como ferramentas para estruturação de cursos na área da Engenharia Geotécnica, bem como não se observaram relatos sobre o desenvolvimento de ROEs com conteúdo específico para este domínio.

Neste artigo discute-se a aplicação Web ENGEO, que por ser uma ferramenta de gestão de informação, auxilia o professor a otimizar o planejamento de seus cursos, bem como armazenar e estruturar o conhecimento envolvido na sua área de atuação. Além disso, espera-se que a adoção da aplicação ENGEO como ferramenta de apoio à prática docente provoque uma mudança na cultura ou fomente discussões a respeito dos modelos de ensino-aprendizado adotados no ensino de Engenharia da UFRGS. Além da motivação gerada pela possibilidade de desenvolvimento de um sistema de informações que propusesse uma solução original e funcional para a gerência e oferta de conteúdo (recursos eletrônicos em diversos formatos, como vídeos, animações, hipertexto, textos e ilustrações), também se teve como motivação o desejo de tornar acessível ao usuário o conhecimento sobre a prática de Engenharia Geotécnica, particularizado para Engenharia de Fundações. Com a oferta de conteúdo documentando situações específicas de obra, como, por exemplo, execução de fundações e suas patologias, podese contextualizar o aprendizado, disponibilizando situações práticas que complementem a teoria apresentada em sala de aula.

A introdução de sistemas de informações e de tecnologias da informação, das TICs, no seu sentido mais amplo, na prática do professor, independentemente da estratégia de uso, propicia acessibilidade, flexibilidade e disponibilidade das informações e dos recursos educacionais aos alunos e auxilia a estruturação e organização do conhecimento envolvido no domínio de aplicação. Contudo, o fato de poder contar com um sistema de informação baseado na Web para disponibilização de conteúdo e informações de cursos e disciplinas não significa melhoria na qualidade do ensino.

Além da motivação gerada pela possibilidade de desenvolvimento de um sistema de informações que propusesse uma solução original e funcional para a gerência e oferta de conteúdo (recursos eletrônicos em diversos formatos, como vídeos, animações, hipertexto, textos e ilustrações), também se teve como motivação o desejo de tornar acessível ao usuário, através da aplicação Web ENGEO, o conhecimento sobre a prática de Engenharia Geotécnica, particularizado para Engenharia de Fundações, através da 
produção de conteúdo documentando situações específicas de obra, como, por exemplo, execução de fundações e patologias das fundações.

A produção de recursos para apoiar a prática docente e o aprendizado tomou outra dimensão com o surgimento da Web. As estratégias que devem ser adotadas para as atividades tanto de ensino quanto de aprendizado estão sendo impactadas pelas novas TICs bem como pelos processos de comunicação baseados em serviços oferecidos em rede de computadores, sendo que TAROUCO $(2001$, p. 7$)$ diz que:

\begin{abstract}
A tecnologia de informação e comunicação atualmente disponível oferece novas possibilidades para o processo de ensino-aprendizagem envolvendo a mediação do processo de comunicação por meio de serviços baseados no WWW, vídeo interativo e realidade virtual. A tecnologia passa a funcionar como elemento catalizador e transformador [...] viabilizando o desenvolvimento de um ambiente de ensino-aprendizagem que, apoiado pela Internet, possa atuar como instrumento de auxílio à uma prática pedagógica diferenciada.
\end{abstract}

Diversos sistemas comerciais e acadêmicos já foram desenvolvidos e as empresas e grupos de pesquisa continuam investindo tempo e recursos no aperfeiçoamento destes produtos. Cada um modelado com características diferentes, que giram em torno de discussões de cunho pedagógico e tecnológico. A cada tecnologia que surge, novas possibilidades pedagógicas são abertas. SCHLEMMER (2001) relata que a decisão em adotar um sistema para suporte ao ensino baseado na Web oscila entre reproduzir o modelo presencial ou adotar iniciativas de mudanças (grifo do autor) .

Neste sentido, a proposta do presente trabalho é agregar as TICs em um sistema inovador. LOISELLE (2002) sugere que o uso da Web possibilita o acesso a conteúdos diversos em uma variedade de formatos e que este material pode enriquecer as experiências de aprendizado, desde que as tecnologias de informação e comunicação sejam utilizadas em um contexto pedagógico que aproveite a liberdade que as TICs proporcionam, ou de outra forma elas apenas reproduzem o presencial. VICARI (2003 p.155) complementa afirmando que "todo programa pode ser considerado um programa educacional, desde que utilize uma metodologia que o contextualize no processo de ensino-aprendizagem".

Assim, novas soluções implicam em mudanças nas posturas de professores e alunos em relação a seus papéis no processo de ensino e aprendizagem, que segundo SCHLEMMER (2001) implica em novas práticas pedagógicas e novos modos de produção e tratamento de informações e conteúdos. (grifo do autor)

É consenso que a Web e as TICs se apresentam como alternativas para melhorar as condições de aprendizagem bem como estruturar conteúdos de cursos tradicionalmente presenciais, além de agregar valor ao trabalho do professor e facilitar a gerência recursos eletrônicos. Como já mencionado, existem inúmeras iniciativas de desenvolvimento de sistemas que reúnem uma série de recursos para estruturação de conteúdos de cursos na Web. Contudo, segundo SANTAROSA (2001), em muitos casos envolvem "restrições e limitações pertinentes a um ambiente proprietário".

Através do presente projeto pretende-se tornar permanentemente acessível o conhecimento ao alcance do aluno ou usuário do ENGEO, através da oferta da aplicação Web juntamente com a base de conhecimento proporcionada pelos Objetos Educacionais do repositório e pelas registros armazenados na base de informações. As TICs e a Web se apresentam hoje como ferramentas para desenvolvimento de uma 
modalidade de educação que possibilita a inovação dos procedimentos de ensino, o desenvolvimento de uma educação extra-escolar que utiliza os diversos meios de comunicação, possibilitando o acesso de ao conteúdo de locais fora do ambiente da sala de aula tradicional.

\section{Aplicações Web educacionais e o uso das TICs}

CHARLIER (2002) e TEIXEIRA (2002) ressaltam que na produção de aplicações Web para apoio ao ensino ocorre muitas vezes a transposição dos recursos pedagógicos usados presencialmente para uma outra forma de apresentação, que invariavelmente segue o mesmo modelo, simplesmente substituindo a comunicação face-a-face pela comunicação on-line ou o material impresso pelo eletrônico, não explorando os recursos específicos oferecidos pelas TICs e pela Internet.

Com base na afirmação acima, além de disponibilizar conteúdos do domínio, a aplicação (destinada prioritariamente a alunos de graduação e pós do curso de Engenharia Civil) tem também como meta, testar as estratégias desenvolvidas, para justificar (ou não) a expansão da mesma idéia para outras áreas. Em especial, para testar a chamada natureza interativa e flexível da Internet, oferecendo aos usuários/estudantes acesso remoto para conteúdo com várias possibilidades de acesso, por área de interesse dentro do domínio, por tipos de mídia específico ou por assunto.

LOISELLE (2002) cita o acesso a ferramentas de pesquisa e filtragem de informação em aplicações educacionais baseadas na Web como uma característica desejável para dar suporte ao usuário na busca pessoal de informações. Mecanismos de busca interna e externa, glossário e links com dicionários ou sistemas de pesquisa bibliográfica são exemplos deste tipo de ferramenta.

Outra característica desejável é a representação do conteúdo tratado através de múltiplos formatos, pois "a utilização de estímulos complementares em um sistema multimídia pode facilitar a aprendizagem. Assim, a inlusão de elementos textuais, gráficos, auditivos e visuais [...] permite que alunos com estilos congnitivos diferentes possam optar pelo modo de apresentação que mais lhes convier." (LOISELLE, 2002, p. 114)

Complemetando a citação de LOISELLE, cada mídia ou ferramenta de interação/cooperação oferecida ao aluno no ambiente virtual deverá contar com a respectiva equação do que ALAVA (2002) identifica como uma potencialidade da educação em ambiente virtual: o binômio método/mídia. Isso significa que cada tecnologia escolhida pelo planejador/professor deve agregar ao universo pedagógico sua própria contribuição. Um vídeo, cuja característica normalmente costuma estar associada a uma postura de simples recepção do aluno, pode ter sido planejado para mostrar a ele os detalhes do mundo real, da prática profissional à qual o conteúdo se refere, através da documentação de imagens e, se possível, a identificação da relação existente entre essa realidade e o universo de conteúdos.

Neste contexto, um aluno é potencialmente, e simultaneamente, um professor de si mesmo e de seus colegas no mundo virtual, com os quais estiver interagindo, dependendo, é claro, de seu próprio envolvimento e de sua capacidade de participar de operações desse tipo. Neste mesmo contexto é importante que o professor aprenda a operar através dessa nova tecnologia, que demanda destreza, rapidez de raciocínio e ainda, no seu caso, a atenção de um mediador do mundo virtual, se ater aos objetivos de cada unidade e não perder de vista o nível dos alunos e o universo global dos conteúdos. 


\section{Método de desenvolvimento da aplicação web engeo}

A decisão de quais tecnologias utilizar para desenvolvimento e implementação da aplicação foi a primeira etapa do planejamento, e portanto, anterior ao trabalho de programação do software. Esta escolha tem implicação direta na arquitetura de hardaware e software necessário para a disponibilização do software, sendo que estrategicamente optou-se pelo acesso compartilhado pela WEB.

A oferta da aplicação pela Web permite o uso de sistemas de banco de dados e aplicações ${ }^{\mathrm{i}}$ que acessam e disponibilizam conteúdo dinâmico ${ }^{\mathrm{ii}}$, além de diminuir a distância entre o usuário e a informação (TEIXEIRA, 2002, p. 25) e que segundo Loiselle (2002, p. 108) "[...] pode enriquecer as atividades de aprendizagem e de ensino."

A aplicaçao WEB ENGEO segue as referências de arquitetura definidas pela especificação da tecnologia Java Servlet (JAVA COMMUNITY PROCESS, 2004-b) que diz que uma aplicação WEB pode conter páginas JSP que negociam requisições e geram conteúdo dinâmico; Servlets que negociam requisições e geram conteúdo dinâmico; componentes JavaBeans que encapsulam comportamentos e estados; HTML estático, DHTML, XHTML, XML, e páginas similares; Java Applets, componentes JavaBeans, e classes Java arbitrárias; ambiente de execução JRE rodando no cliente através do plugin Java Web Start; e ambiente de execução JRE rodando no servidor, sendo este último obrigatório. A aplicação WEB ENGEO atende a específicação pois roda páginas JSP e possui o JRE rodando no servidor da aplicação. A arquitetura que compõe o ENGEO pode estar distribuída fisicamente em vários computadores ou toda infra-estrutura de software pode estar alocada em um único computador, dependendo é claro, dos recursos que se dispõe. A estrutura geral da aplicação Web ENGEO pode ser vista na Figura 1, sendo que esta arquitetura foi a implementada, ou seja, todos os serviços instalados em um único computador. $\mathrm{O}$ ambiente de produção ${ }^{\mathrm{iii}}$ é composto de um servidor HP Pro Liant ML110, com dois discos de 40Gb, processador Pentium IV $2.8 \mathrm{GHz}$ e $768 \mathrm{Mb}$ de memoria RAM. Neste servidor de produção temos instalado o container Web ${ }^{\text {iv }}$ Jakarta Tomcat V. 5.0.27, que disponibiliza acesso a JavaServer Pages (JSP) e Servlets, duas tecnologias Java para Web, o SGBD MySQL V. 4.0.17 que armazena as informações usadas pelo ENGEO, o servidor de streaming de mídia Helix Server V.9 que serve arquivos de áudio e vídeo através de fluxo contínuo de informação e a plataforma J2SE 5.0 que dá suporte para que os componentes baseados em Java sejam executados. 


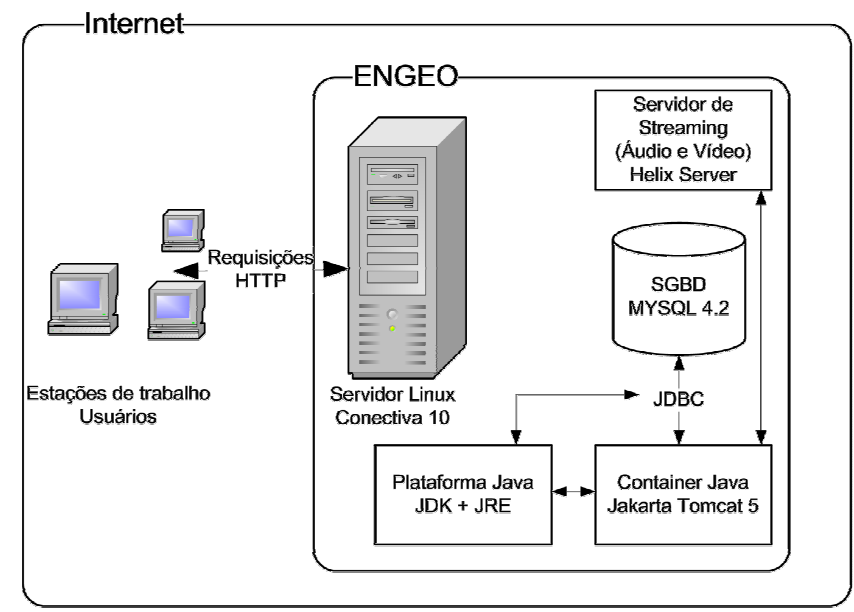

Figura 1: Arquitetura geral da aplicação Web ENGEO

Nos próximos capítulos cada uma das partes que compõe o ENGEO serão melhor detalhadas, bem como sua integração.

\section{Descrição da aplicação web engeo}

Este capítulo mostra a área pública do ENGEO, que compreende-se pela área livre para acesso a qualquer usuário, bastando apenas conexão com a Internet e um navegador Web. Adicionalmente serão necessários softwares de visualização de documentos PDF, de vídeos no formato RealMedia e de animações no padrão Flash.

Todos estes padrões possuem visualizadores gratuítos e são de fácil instalação, sendo que as últimas versões de navegadores Web já vem com o plug-in Flash incorporado. Caso contrário, pode-se baixá-lo do site da fabricante Macromedia. O mesmo acontece com o Real Player, necessário para visualização dos vídeos e dos visualizadores de PDF, sendo o Acrobat Reader o mais popular deles.

Duas seções do ENGEO são protegidas por senha, a seção livros, e a seção de administração do ENGEO. A seguir será descritas a área pública da aplicação ENGEO.

\section{Área pública do ENGEO}

Aárea pública do ENGEO pode ser acessada pelo endereço http://iate.ufrgs.br:8080/engeo/ sendo que interface de entrada com o índice pode ser visto na Figura 2.

A interface do ENGEO foi estruturada para oferecer ao usuário acesso direto a dois grupos de conteúdo. Através de um índice de opções localizado na lateral esquerda da janela do navegador, o usuário pode acessar informações relativas a disciplina Fundações e acesso a ferramentas e conteúdos de apoio que cobrem o domínio de conhecimento desta área. 


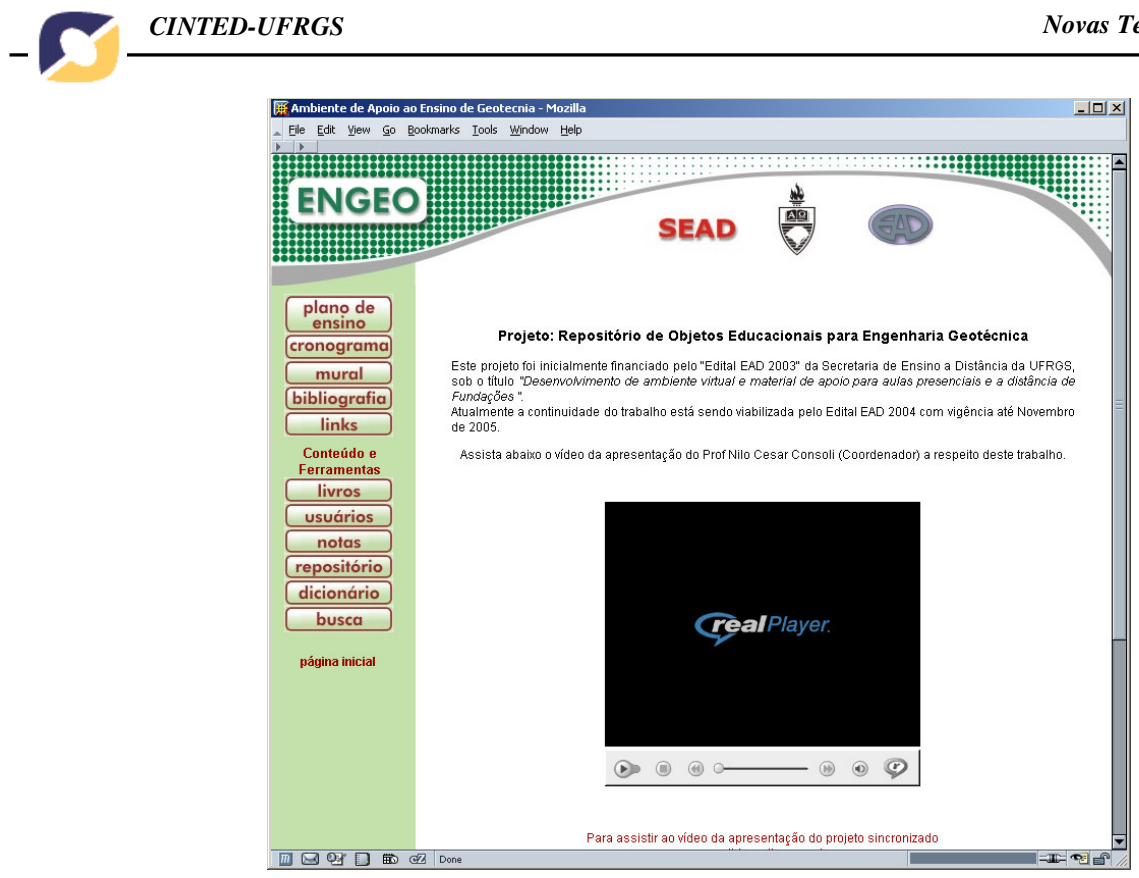

Figura 2: tela inicial do sistema ENGEO

Neste índice o usuário tem acesso às informações da disciplina a partir do primeiro grupo de botões na parte superior, como plano de ensino, cronograma, mural de informações, bibliografia recomendada, links para sites WEB referentes ao domínio. No segundo grupo de botões tem-se acesso à ferramentas e conteúdos para usuários do sistema, sendo eles, livros, lista de usuários e seus endereços de e-mail, notas atribuídas as atividades da disciplina para cada aluno, repositório de objetos educacionais, dicionário de termos técnicos de geotecnia e sistema de busca de conteúdo.

Um das ferramentas implementadas no ENGEO, como mencionado no parágrafo anterior, é o Repositório de Objetos Educacionais (ROE). A partir do botão repositório o usuário tem acesso a dois menus que representam taxonomias de busca de objetos educacionais $(\mathrm{OE})$ no repositório. Estes menus permitem buscar conteúdo por tipo de material ou por tópicos que são abordados no conteúdo do ENGEO. Estes tópicos foram definidos em conjunto com o prof. Nilo Cesar Consoli que é coordenador de um projeto que dá suporte à produção de conteúdos para o ENGEO. As telas de entrada do repositório com o menu de busca por materiais e a tela com o menu de busca por tópico são vistas na Figura 3. Estas opções aparecem para o usuário no momento em que ele passa o mouse sobre as frases que aparecem na tela: Busca por material ou Busca por tópico. 


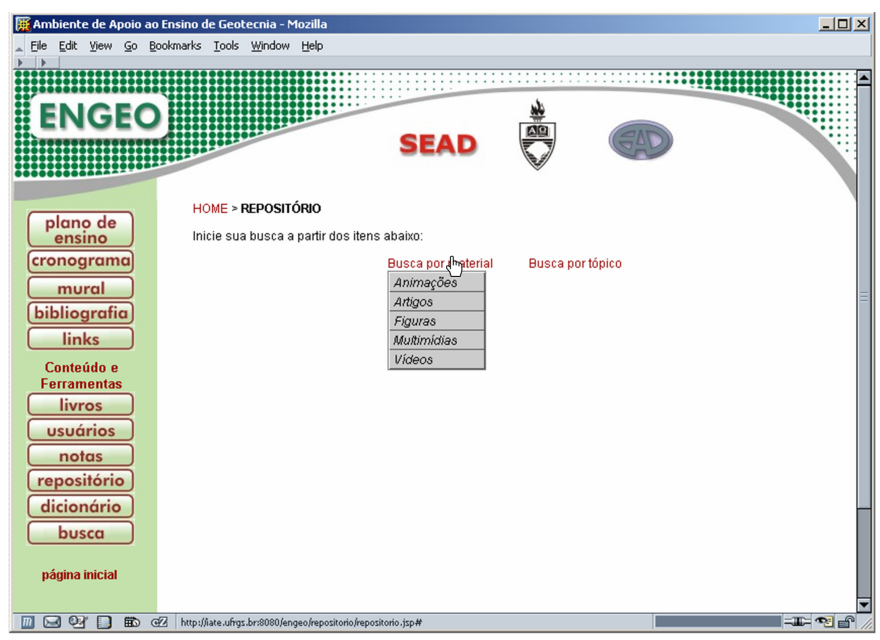

Figura 3: tela mostrando as opções de busca por material no repositório.

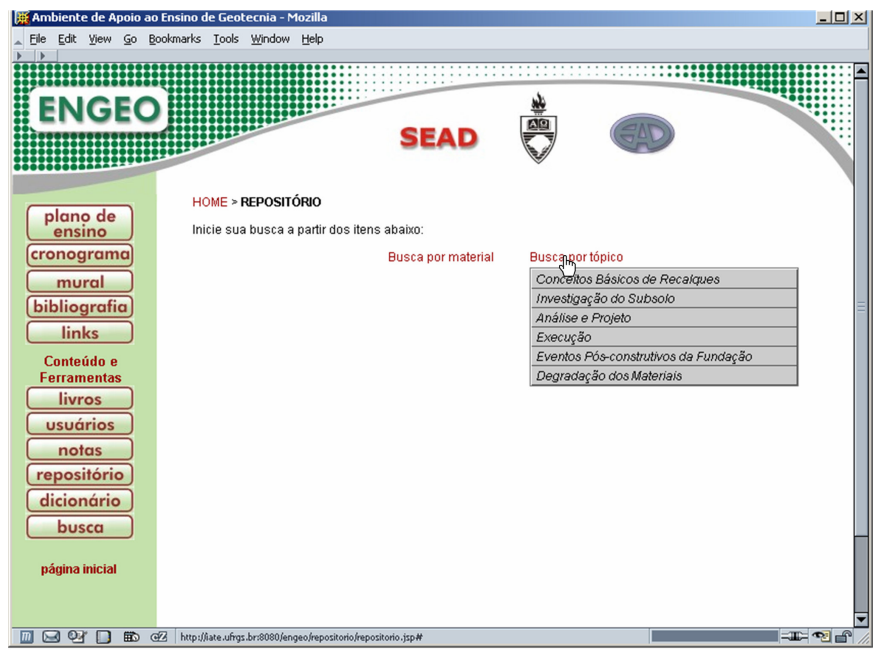

Figura 4: tela mostrando as opções de busca por tópico no repositório.

Em Busca por material o usuário tem a opção de buscar OEs por tipo de conteúdo, sendo que as opções a disposição são animações, artigos, figuras, multimídias e vídeos.

Ao se realizar uma busca por vídeos, por exemplo, tanto por restrição por tópicos quanto pela totalidade de registros de vídeos no ENGEO, o usuário recebe uma página listando os registros encontrados. Esta página contém informações como quantidade de registros encontrados, título atribuído ao vídeo, autores, palavras-chave e um link que leva a mais detalhes e ao vídeo propriamente dito. Estes detalhes são vistos Figura 5.

Clicando em Mais detalhes... o usuário segue para a página onde poderá assitir o vídeo e obter informações extras como tempo total do vídeo, tempo do início das imagens relevantes na linha de tempo do vídeo, descrição do assunto abordado e formato do arquivo digital do vídeo (Figura 6). 


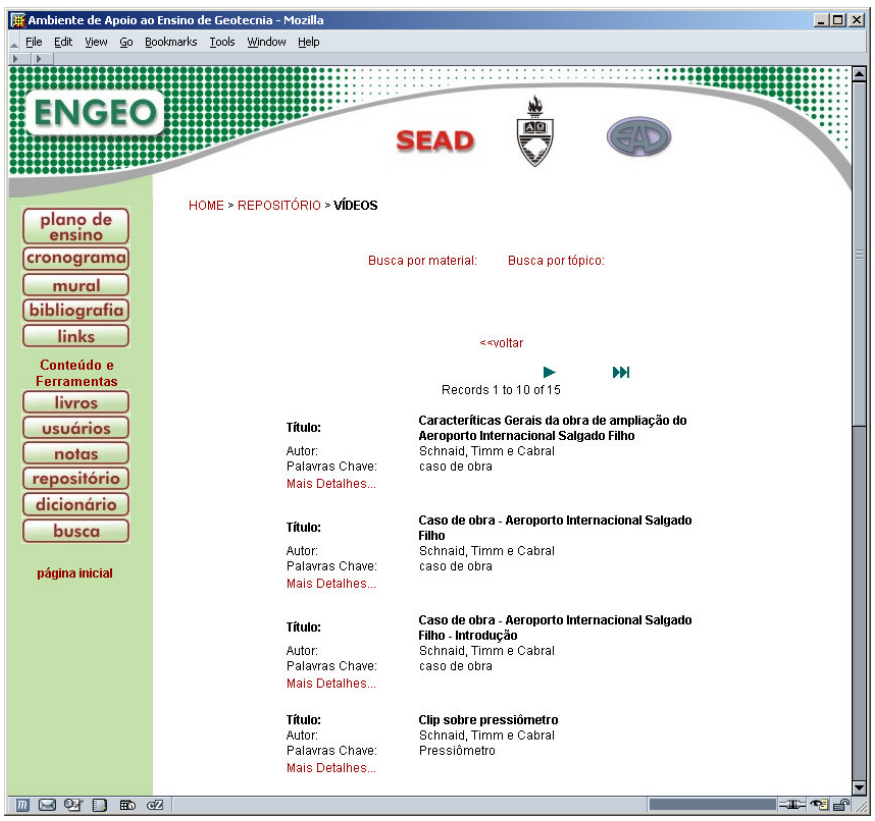

Figura 5: lista de registros encontrados para busca por vídeos.

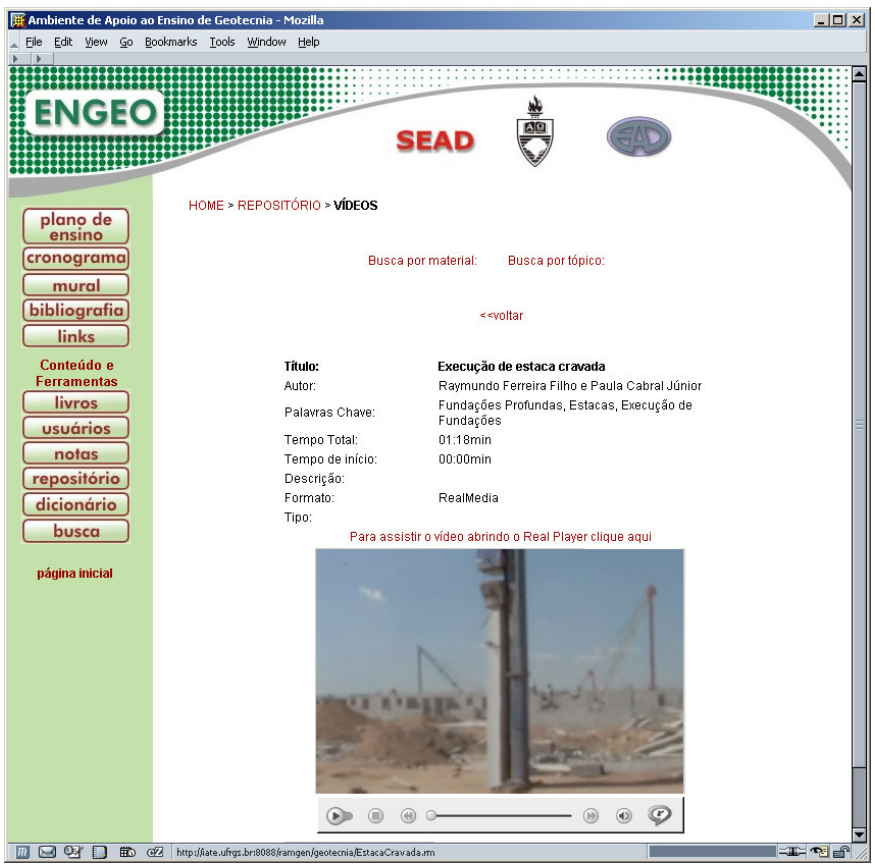

Figura 6: página que mostra detalhes descritivos do vídeos bem como o próprio vídeo.

Os detalhes já mencionados a respeito de buscas valem para todos recursos educacionais do ROE. Além disso, tem-se a disposição do aluno um dicionário inglês/português de expressões técnicas da área da Engenharia Geotécnica e dois livros eletrônicos sobre patologia das fundações e sobre ensaios de campo, sendo que estes recursos são acessados pelos respectivos links do índice principal. 


\section{Conclusões}

O objetivo do presente trabalho foi desenvolver uma aplicação dinâmica baseada na Web, chamada ENGEO, composta de um repositório de objetos educacionais, um sistema de gestão dos recursos armazenados na aplicação, e ferramentas para auxiliar a busca de informações nesta aplicação e na Web, com a função de oferecer suporte ao estudo do conteúdo referente ao domínio da Engenharia Geoténica, em especial da disciplina Fundações da grade curricular do curso de Engenharia Civil da Universidade Federal do Rio Grande do Sul (UFRGS).

Na presente pesquisa pretendeu-se fornecer meios para a estruturação do conhecimento através de uma ferramenta interativa e dinâmica, onde o usuário pudesse buscar conteúdos e obter informações a respeito de disciplinas do curso de Engenharia Geotécnica. A implementação da aplicação Web ENGEO foi particularizada para uma disciplina, apesar de sua estrutura estar preparada para comportar um conjunto de disciplinas.

Também se teve como objetivo a produção de objetos educacionais específicos para a disciplina Fundações, como por exemplo, o desenvolvimento de animações de processos de investigações de solos e de casos de patologia de fundações, produção de videos para gerar acervo de informações de obras geotécnicas em suas diferentes fases de execução e informações visuais através imagens estáticas.

A implementação do ENGEO visa:

- introduzir e incentivar a utilização de sistemas baseados na Web para compartilhamento de conteúdo das disciplinas, lançando mão de toda a flexibilidade que a Web proporciona;

- $\quad$ implementar tecnologias de informação e comunicação em aplicações para fins educacionais e fomentar discussões a respeito;

- $\quad$ contribuir para a inovação da prática pedagógica no ensino de Engenharia;

- $\quad$ auxiliar o aluno no acesso a conteúdos fora do ambiente presencial e o professor a gerir e estruturar conteúdos em meio digital.

A aplicação ENGEO está permeada pela discussão do uso pedagógico das TICs e da Web e seu desenvolvimento é influenciado por está discussão, apesar do presente trabalho ter tido como objetivo a descrição do desenvolvimento do produto e não avançar em discussões a respeito de suas estratégias de uso.

\section{Bibliografia}

ALAVA, S. e colaboradores. Ciberespaço e formações abertas: rumo a novas práticas educacionais?. Porto Alegre: Artmed, 2002.

FREE SOFTWARE FOUNDATION. Disponível em <http://www.fsf.org/>. Acesso em Fev. de 2004. 
JAVA COMMUNITY PROCESS. JSR 54: JDBC ${ }^{\text {TM }}$ 3.0 Specification. Palo Alto, CAUSA: Sun Microsystems Inc, 2001.

JAVA COMMUNITY PROCESS. JSR 154: Java ${ }^{\text {TM }}$ Servlet 2.4 Specification. Santa Clara, CA-USA: Sun Microsystems Inc, 2003.

JAVA COMMUNITY PROCESS. JSR 245. JavaServer ${ }^{\text {TM }}$ Pages 2.1. Santa Clara, CA-USA: Sun Microsystems Inc, 2004-b.

LOISELLE, J. A exploração da multimídia e da rede Internet para favorecer a autonomia dos estudantes universitários na aprendizagem. In: Alava, S. e colaboradores. Ciberespaço e formações abertas: rumo a novas práticas educacionais?. Porto Alegre: Artmed, 2002.

MORAN, J. M. Mudanças na Comunicação Pessoal: gerenciamento integrado da comunicação pessoal, social e tecnológica. São Paulo: Paulinas, 1998.

MORAN, J. M. Ensino e aprendizagem inovadores com tecnologia. Revista Informática na Educação: Teoria e Prática, Vol. 3, nº 1, p. 137-144, Porto Alegre, Set. de 2000 .

SCHLEMMER, E.; FAGUNDES L.C.. Um proposta para Avaliação de Ambientes Virtuais de Aprendizagem na Sociedade em Rede. Informática na Educação: Teoria e Prática. Vol. 4, nº 2, p. 25-36. Dez. de 2001.

STALLMAN, R. UNESCO and Free Software. Disponível em $<$ http://portal.unesco.org/ci/en/ev.phpURL_ID=13803\&URL_DO=DO_TOPIC\&URL_SECTION=201.html >. Acesso em Março de 2004.

SUNSOURCE.NET. What is Open Source. Disponível em $<$ http://www.sunsource.net>. Acesso em Fevereiro de 2005.

TAROUCO, L. M. R. Plataformas para suporte a Educação a Distância. Informática na Educação: Teoria e Prática. Vol. 4, nº 2, p. 7-13. Porto Alegre, Dez. de 2001.

TAROUCO, L. M. R.; FABRE M. J. M.; TAMUSIUNAS, F. R.. Reusabilidade de objetos educacionais. RENOTE - Revista Novas Tecnologias na Educação: II Ciclo de Palestras sobre Novas Tecnologias na Educação. Porto Alegre, 2003.

TEIXEIRA, A. C. Internet e democratização do conhecimento: repensando oprocesso de exclusão social. Passo Fundo: UPF, 2002.

VICARI, R. M.; GIRAFFA, L. M. M. Fundamentos de Sistemas Tutores Inteligentes. In: Barone, D.; et alii. Sociedades artificiais: a nova fronteira da inteligência nas máquinas. Porto Alegre: Bookman, 2003.

\footnotetext{
i Termo da ciência da computação, aqui usado como sinônimo de programa ou software

ii Conteúdo dinâmico se adapta ao momento de acesso do usuário da aplicação WEB e geralmente as informações estão armazenadas em bancos de dados. Um exemplo é o acesso a saldos de contas correntes em Bancos online ou em caixas eletrônicos.

iii Ambiente de produção é aquele em que disponibiliza as versões finais dos produtos. Ambientes de desenvolvimento são aqueles onde ocorrem todos os testes em todas as etapas até se chegar a uma versão estável e final de um produto. Geralmente se tem duas arquiteturas de hardware e software idênticas ou com os mesmos requisitos para rodar uma dada aplicação, uma para desenvolvimento e outra para produção.
} 
${ }^{\text {iv }}$ Container Web é uma implementação do JCP 154, é um servidor Web que trabalha com tecnologias Java. 